\title{
A novel method for the age estimation of Saddletail snapper (Lutjanus malabaricus) using Fourier Transform-near infrared (FT-NIR) spectroscopy
}

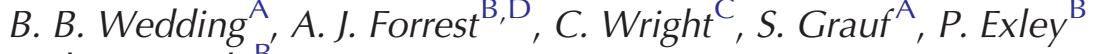 \\ and S. E. Poole \\ A Rapid Assessment Unit, Crop and Food Science, Department of Agriculture, \\ Fisheries and Forestry, Cairns, Qld 4870, Australia. \\ ${ }^{\mathrm{B}}$ Crop and Food Science, Department of Agriculture, Fisheries and Forestry, \\ Coopers Plains, Qld 4108, Australia.

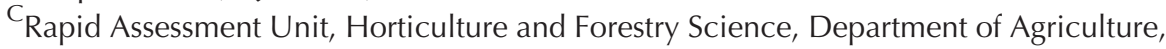 \\ Fisheries and Forestry, Mareeba, Qld 4880, Australia. \\ DCorresponding author. Email: andrew.forrest@qld.gov.au
}

\begin{abstract}
Near infrared (NIR) spectroscopy was investigated as a potential rapid method of estimating fish age from whole otoliths of Saddletail snapper (Lutjanus malabaricus). Whole otoliths from 209 Saddletail snapper were extracted and the NIR spectral characteristics were acquired over a spectral range of $800-2780 \mathrm{~nm}$. Partial least-squares models (PLS) were developed from the diffuse reflectance spectra and reference-validated age estimates (based on traditional sectioned otolith increments) to predict age for independent otolith samples. Predictive models developed for a specific season and geographical location performed poorly against a different season and geographical location. However, overall PLS regression statistics for predicting a combined population incorporating both geographic location and season variables were: coefficient of determination $\left(R^{2}\right)=0.94$, root mean square error of prediction (RMSEP) $=1.54$ for age estimation, indicating that Saddletail age could be predicted within 1.5 increment counts. This level of accuracy suggests the method warrants further development for Saddletail snapper and may have potential for other fish species. A rapid method of fish age estimation could have the potential to reduce greatly both costs of time and materials in the assessment and management of commercial fisheries.
\end{abstract}

Additional keywords: Arafura Sea, fish ageing, otolith increments, saddletail snapper.

Received 16 September 2013, accepted 15 January 2014, published online 4 July 2014

\section{Introduction}

Reliable fish ageing methods are needed for age-structured stock assessment and sustainable fisheries management. One of the current standard practices for fish ageing consists of counting annual rings (annuli) on resin mounted and sectioned otoliths (Secor et al. 1995). This method requires a high degree of competency and experience to achieve accurate results (Cardinale et al. 2000). The time required to prepare a large number of otolith sections can often mount up into days and even weeks to complete before reading. Campana and Thorrold (2001) estimate a minimum of 800000 fish age determinations from otolith sections were conducted in the year 1999, and they speculate that the total number of fish age determinations (using all available methods) is probably closer to two million. This number represents an enormous amount of hours assigned to the preparation of sectioned otoliths, let alone the reading. With an estimated cost in Australia of $\$ 30$ per sample for collection, preparation and reading, there is considerable scope to reduce this using an alternate method such as near infrared (NIR) spectroscopy technology. NIR spectroscopy is rapid and low cost, requires minimal or no sample preparation, and avoids wastage and the need for reagents. Furthermore, the technique is multi-analytical, allowing estimates of several characteristics simultaneously.

The process of age estimation from otolith sections contains two inherent error sources (Campana 2001). First, not all bony or calcified structures in fish provide an accurate age record (Beamish 1979). Second, counting annuli is highly subjective (Boehlert and Yokavich 1984) and rigorous quality control measures are required to maintain consistency and precision to reduce the impact of reader bias.

A new method of age estimation using NIR spectroscopy is investigated in the present study. NIR spectroscopy is a nondestructive technique that uses optical data rather than wet chemistry methods to analyse both solid and liquid products for chemical composition. All organic matter consists of atoms, mainly carbon, oxygen, hydrogen, nitrogen, phosphorus, and sulphur, with a minor amount of other elements (Murray and 
Williams 1987). These molecules vibrate (bend or stretch) at specific frequencies and irradiation of these by an energy source such as NIR light (12 820-4000 $\mathrm{cm}^{-1}$ ) causes some molecules to change their vibrations from one energy level to another. When these transitions occur NIR energy is absorbed at certain frequencies, coinciding with those of a molecular grouping in the material being scanned (Murray and Williams 1987). NIR spectroscopy techniques, and subsequent analysis, harnesses and translates these vibrations into simple, very rapid analytical procedures.

NIR spectroscopy has received considerable attention over the years for analysis of constituents or parameters in many industries, including agricultural, pharmaceutical, industrial and food sectors. The technology has been extensively employed in the assessment of plant materials for many constituents including: oil content (Wedding et al. 2009); dry matter (Wedding et al. 2011); and nitrogen content (McClure et al. 2002). Seafood applications include determination of freshness (Nilsen et al. 2002), muscle pigment (Folkestad et al. 2008), fat content (Solberg et al. 2003; Wold et al. 1996) and moisture (Wold and Isaksson 1997).

NIR spectroscopy is a secondary method of determination and therefore must be calibrated against a primary reference method, in this instance age estimates (based on traditional sectioned otolith increments) to develop a calibration or predictive model. The use of NIR spectroscopy involves developing a predictive model by scanning the material of interest, and comparing the samples spectral data to the reference data obtained from the same material using traditional techniques. This process requires a large number of samples, which must cover the range of biological variability of future samples to attain an acceptable level of accuracy from the predictive model. The successful application of NIR spectroscopy to fish age estimation would greatly reduce the time taken to prepare the otoliths for reading as compared to the traditional sectioned method for measuring increments, enabling the reading process to be mechanised, as well as removing subjectivity and the risk of reader bias. The NIR technique for this application requires little sample preparation and clean whole dry otoliths can be directly presented for NIR spectroscopy assessment. However, errors associated with the reference method will inherently perpetuate through the predictive models and be reflected in the predictive error. Thus, the more accurate and precise the reference method (i.e. traditional sectioned method), the more accurate and precise the NIR calibration model will be.

The present study investigates the use of NIR spectroscopy to scan whole unprocessed otoliths and develop a predictive model to estimate the age of a group of wild-caught Saddletail snapper, which have previously been shown to have otolith increments that can be used for age estimation (Newman 2002). The NIR spectra is directly compared to the visual age estimates, based on increment counts obtained from standard methods of ageing otolith cross-sections.

\section{Materials and methods}

Otoliths were obtained from 209 Saddletail snapper landed by a trawl vessel within the Northern Finfish Fishery as part of another research project (Forrest et al. 2010). This fishery is co-managed by the Commonwealth Government of Australia and the Northern Territory Government, and extends from the Northern Territory border with Western Australia $\left(129^{\circ} \mathrm{E}\right)$ east to the Queensland border $\left(138^{\circ} \mathrm{E}\right)$ and north 200 nautical miles out to the boundary of the Australian Fishing Zone (AFZ). Of these, 100 samples were collected during April 2009 (post-wet season) and 109 were collected during November 2009 (postdry season). This collection of samples from different times of the year was simply due to their availability on the back of the previous mentioned project (Forrest et al. 2010). Fishing was conducted in the eastern end of the Arafura Sea, adjacent to the Gulf of Carpentaria. Fishing was not conducted in the same location for both trips. The exact location of fishing effort has not been reported due to commercial sensitivities. Fish were chilled and frozen onboard, and transported to Coopers Plains (Brisbane, Queensland) after unloading in Darwin, Northern Territory.

Saddletail snapper were further processed at the Health Food Sciences Precinct in Coopers Plains. Fish were thawed and filleted as part of the previous mentioned project (Forrest et al. 2010). After filleting had been completed, otoliths were removed from the heads of the fish and washed in deionised water. After washing, otoliths pairs were allowed to air dry and were then transferred to $10 \mathrm{~mL}$ plastic vials for storage.

Saddletail snapper otoliths were examined for age estimation based on increment counts with the assistance of Fisheries Queensland staff from Southern Fisheries Centre, Deception Bay, Queensland, using the standard method of increment determination of otolith cross-sections (Fisheries-Queensland 2009). The left otolith of each fish was used for this determination. The right side otolith was sent to the Rapid Assessment Unit at the James Cook University in Cairns, Queensland for NIR spectra collection. Previous studies conducted by the authors have found no systematic bias in the predictions between otoliths taken from the left and right sides (FRDC 2013).

Diffuse reflectance spectra of individual whole, dried otoliths were collected using the integrating sphere and sample wheel system on a Bruker multi-purpose analyser (MPA), Fourier Transform (FT) NIR spectrophotometer (Bruker Optics, Ettlingen, Germany; operating software: OPUS version 6.5) in the $12500-3597 \mathrm{~cm}^{-1}$ range. All otolith samples were placed with the same orientation (convex down) in the sample quartz glass vials in preparation for spectra capture. Thirty sample vials at a time were placed onto the sample wheel to be scanned automatically for spectra collection. The loading process takes $\sim 5 \mathrm{~s}$ per sample. In obtaining each sample spectrum, 32 scans at a resolution of $8 \mathrm{~cm}^{-1}$ were collected and averaged. The assessment was conducted in a room exposed to minimal light with the aim of reducing contact with external illumination. The collection of NIR spectra for this particular instrument configuration, resolution and average number of scans takes $\sim 25 \mathrm{~s}$ per sample.

A multivariate data analysis software package 'The Unscrambler' Version 9.8 (Camo, Oslo, Norway) was used to develop partial least square (PLS) calibration models between the reference otolith age estimation of growth bands (increment counts) and the FT-NIR spectra. PLS regression attempts to establish a correlation between the spectral data and the otolith 
age-reference dataset (increment counts) in order to find the optimal model. Simply, the calibration equation or model of the NIR and chemical loadings were combined mathematically to yield the calibration model for analysis of unknown samples.

Prior to analysis, raw NIR spectral data often needs to be mathematically transformed to remove defects observed in the spectra (i.e. noise, base line drift etc). A typical raw absorbance spectrum for Saddletail snapper (post-dry and post-wet) is shown in Fig. 1. Various transformations were applied to the spectral data and the effect on model performance investigated. For all calibration models presented, the spectral data was transformed before model development using a combination of a 25-point Savitsky Golay smooth (moving average) and a first derivative transformation. Validation of the model is carried out to ensure that the model accurately predicts the property of interest (i.e. increment counts based on the traditional sectioned method) in samples not included in the calibration process. PLS calibration model performance was based on the coefficient of determination $\left(R^{2}\right)$ statistic; root mean square error of cross-validation (RMSECV); root mean square error of prediction (RMSEP); bias (average difference between predicted and reference values), and the standard deviation ratio (SDR is the ratio of the standard deviation of the dataset with the RMSECV or RMSEP). The SDR statistic is a measure of the ability of a NIR model to predict a constituent and enables comparison of model performance across populations with

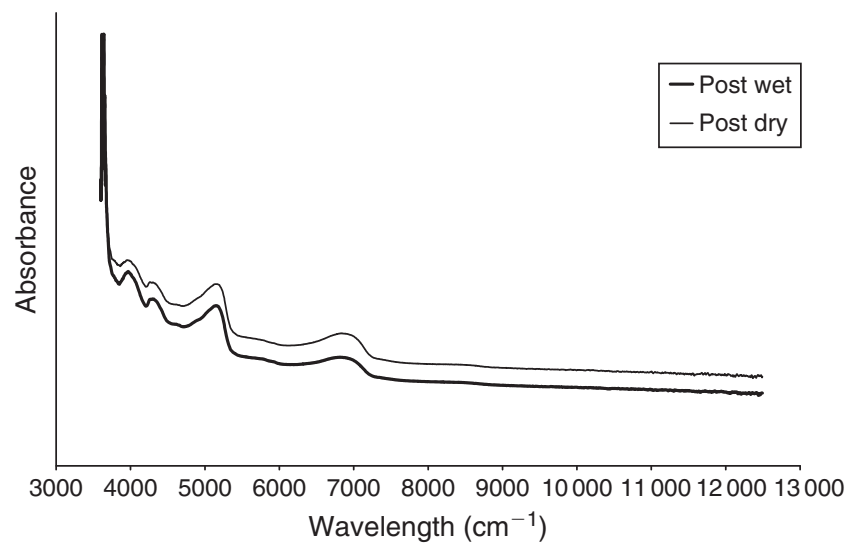

Fig. 1. Typical absorbance spectrum for post-dry and post-wet otolith samples. different standard deviations (Bailleres et al. 2002; Golic and Walsh 2006). Full cross-validation (leave-one-out) was used to evaluate the calibration models.

Before the development of the calibration models, the variation of the raw NIR spectral data was investigated using principal component analysis (PCA) and obvious atypical spectra eliminated. PCA was used to reduce the dimensionality of the NIR spectra and investigate any differences between the post-wet (April) and post-dry (November) season samples.

\section{Results}

The PLS calibration model statistics for the two sample populations are displayed in Table 1. Graphically, both calibration models are tightly aligned along the one-to-one line (where predicted and actual values are equal) with few outliers (Fig. 2 and Fig. 3). The calibration models for the post-wet and post-dry populations yielded an $R^{2}$ of 0.94 and 0.93 respectively. The SDR's are in excess of three so the prospect of age estimations are good (McGlone and Kawano 1998). Figures 2 and 3 suggest there is evidence that otolith samples with an excess of an estimated 18 increment counts are being under-estimated in both the post-wet and post-dry season calibration models. This may suggest that a separate model is required to age the older otoliths. Unfortunately there were not enough otolith samples with an excess of an estimated 18 increment counts in the populations collected to test this. Restricting the model to predict only

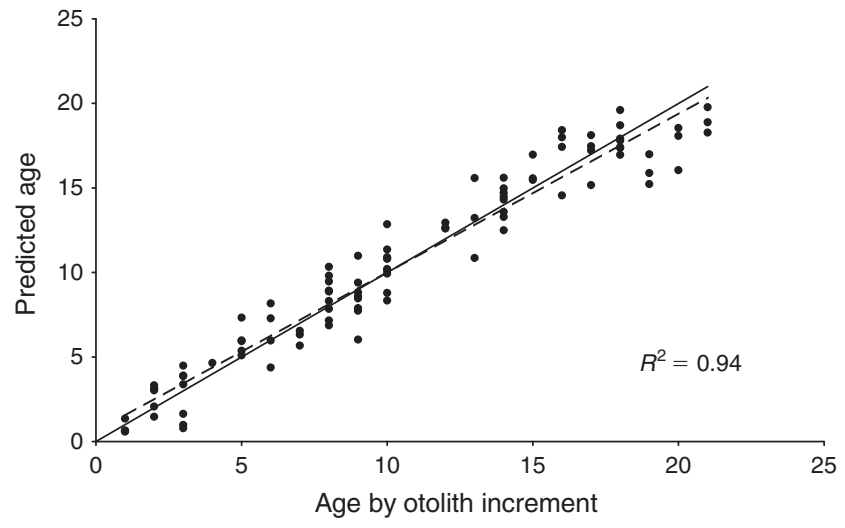

Fig. 2. Calibration model for post-wet season datasets plotted against otolith actual estimated age values (years).

Table 1. Partial least-squares regression calibration and validation statistics for the whole dried otoliths collected over post-wet, post-dry and a combination of both seasons

Note: $\mathrm{SE}=$ Standard Error, LV $=$ Latent Variables

\begin{tabular}{|c|c|c|c|c|c|c|c|c|c|c|}
\hline Calibration set & Prediction set & $\begin{array}{c}\text { Spectra } \\
\text { (outliers removed) }\end{array}$ & $\begin{array}{c}\text { Age range } \\
\text { (Increment counts) }\end{array}$ & $\mathrm{SE}$ & LV & $R^{2}$ & RMSECV & RMSEP & Bias & SDR \\
\hline \multirow[t]{2}{*}{ Post wet } & & 100 & $1-21$ & 0.59 & 3 & 0.94 & 1.42 & & -0.00597 & 4.2 \\
\hline & Post dry & 109 & $2-23$ & 0.47 & 3 & 0.20 & & 4.38 & -4.109 & 1.1 \\
\hline \multirow[t]{2}{*}{ Post dry } & & $109(1)$ & $2-23$ & 0.47 & 4 & 0.93 & 1.30 & & -0.00411 & 3.8 \\
\hline & Post wet & 100 & $1-21$ & 0.59 & 4 & 0.22 & & 5.19 & 4.805 & 1.1 \\
\hline \multirow[t]{2}{*}{ Seasons combined } & & $169(1)$ & $1-23$ & 0.40 & 4 & 0.93 & 1.35 & & -0.00466 & 3.8 \\
\hline & Seasons combined & 40 & $1-21$ & 1.01 & 4 & 0.94 & & 1.54 & -0.0271 & 4.1 \\
\hline
\end{tabular}




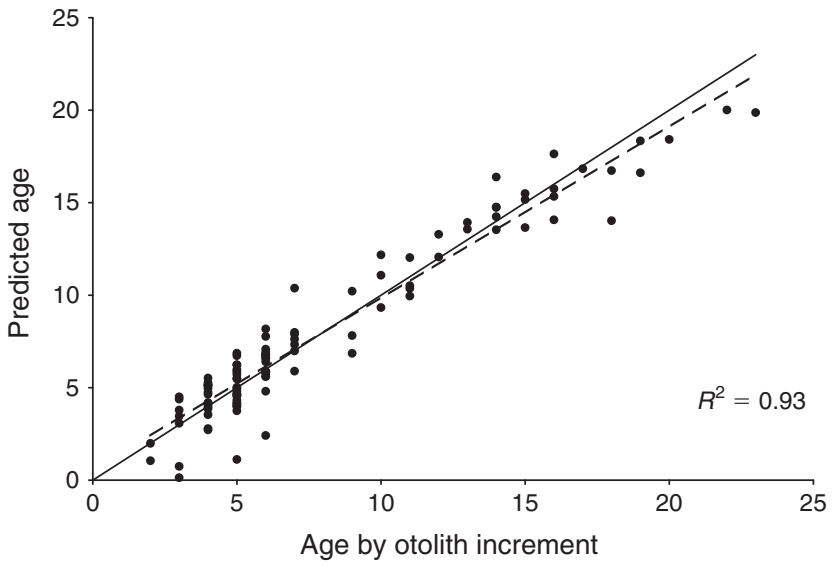

Fig. 3. Calibration model for post-dry season datasets plotted against otolith actual estimated age values (years).

younger otolith samples with an estimated 18 or fewer increments results in improvements to the overall calibration model statistics, showing a reduction in cross-validation error (post-wet $R^{2}=0.95, \mathrm{RMSECV}=1.14$; post-dry $R^{2}=0.92$, RMSECV $=1.20$ ).

The post-wet otolith calibration model was used to predict the post-dry population and vice versa (Table 1) to investigate possible seasonal variables and their effect on the models. The post-wet calibration model could not be used to predict the postdry season population $\left(R^{2}=0.20, \mathrm{RMSEP}=4.38\right)$. Similarly, the post-dry season calibration model was unsuccessful in predicting the post-wet season otolith dataset $\left(R^{2}=0.22\right.$, RMSEP $=5.19$ ).

The shape of the PLS loadings from the calibration models for the post-wet and post-dry samples were similar for the majority of wavelength regions selected. Similarities occurred for both calibrations models in the regions of $6250-4000 \mathrm{~cm}^{-1}$ as a result of the carbonate ion (Gaffey 1986; Hunt 1977; Thomas et al. 2011). Carbonates and hydroxyl (-OH) bearing groups contain strong NIR-active vibrational modes (Hunt 1977; Moron and Cozzolino 2003; Thomas et al. 2011). Correlations were also found within this region related to $-\mathrm{CH}$ combination overtones, $\mathrm{H}_{2} \mathrm{O}$ and - $\mathrm{OH}$ first, second and combination overtones. The main differences observed in the loadings were in the regions of 5850-5710, 6670-6270 and 7380 $7330 \mathrm{~cm}^{-1}$ related to group frequencies of $-\mathrm{CH}$ first overtones and combination overtones, and -NH first overtones, which were not selected in both calibration models.

Investigating this further, the scores plot of PC1 versus PC2 from the PCA revealed that the two otolith populations were distinct from each other, and therefore quite different (Fig. 4). PC1 accounted for $55 \%$ of the total variance while PC2 accounted for $36 \%$. The main separation in the two otolith populations appears to be attributed to PC2 with the majority of post-wet samples having negative loadings and post-dry samples having positive loadings. Figure 5 shows larger peaks in the loadings for PC2 compared to PC1 in two of the three regions identified as being different in the PLS loadings. This separation may be attributed to differences in the otolith microchemistry of

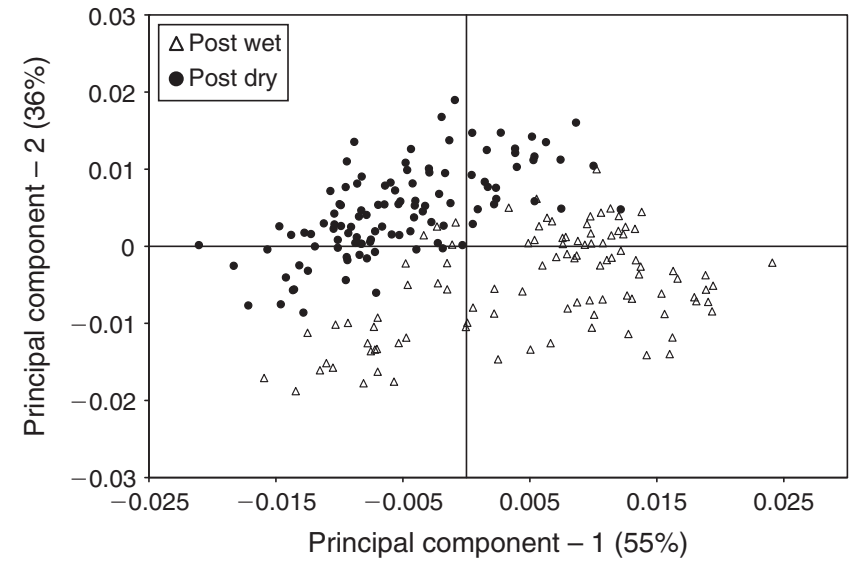

Fig. 4. PCA plot showing separation of post-wet season and post-dry season otolith datasets.

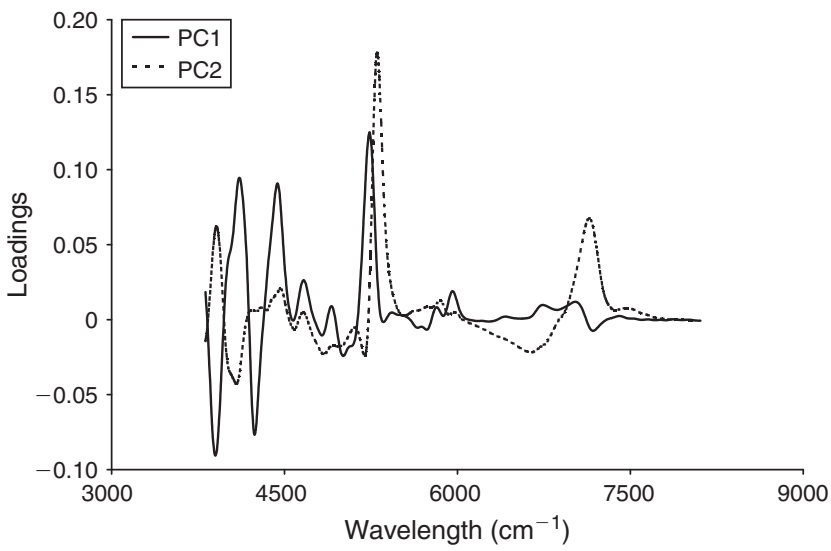

Fig. 5. Loadings derived for $\mathrm{PC} 1$ and $\mathrm{PC} 2$ from the $\mathrm{PCA}$ of otolith samples.

the two sample populations, as a result of seasonal differences or geographical locations.

Subsequently, the two populations were combined to develop a calibration model that improved predictive performance by encompassing the biological variability of the two populations (Table 1). Given the larger number of samples available, the combined dataset was separated into a calibration set $(n=169)$ and an independent validation set $(n=40$, Fig. 6.) rather than cross validating to give a more true indication of predictive ability (Williams 2004).

The PLS calibration model yielded an $R^{2}$ of 0.93 , RMSECV of 1.35 and an SDR of 3.8 for otolith age estimation (Table 1). The validation statistics of the combined dataset delivered an $R^{2}$ of 0.94, RMSECV of 1.54 and an SDR of 4.1 for otolith age. The SDRs are in excess of 3 and as such, the likelihood of an accurate age prediction are good (McGlone and Kawano 1998).

\section{Discussion}

These results demonstrate the potential to predict the age of whole Saddletail snapper otoliths rapidly using NIR 


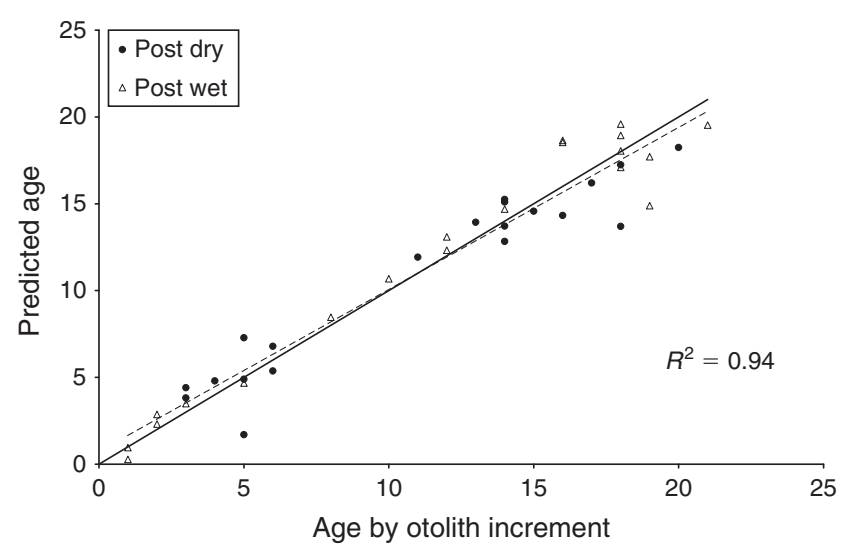

Fig. 6. Combined post-wet season and post-dry season model predictions plotted against otolith actual estimated age values (years).

spectroscopy. The FT-NIR method used in this work has the capacity to conduct up to 150-200 measurements per hour, once a viable predictive model is developed. The calibration results are highly encouraging considering the inherent error associated with the conventional interpretation of the otolith visual age increment counts for estimating age from which these models were developed. Age validation on the basis of radiocarbon derived from nuclear testing is currently one of the best age validation approaches available (Campana 1999). The years 1958 to 1965 are known to be sensitive for $\Delta^{14} \mathrm{C}$-based ageing and bomb radiocarbon ageing of fish during this period are reported to have an accuracy of at least $\pm 1-3$ years; the discriminatory power of samples collected before or after this period is more than an order of magnitude lower (Campana 1999).

The microchemistry of the otolith provides the specific spectral information that is related to otolith age. This therefore requires a substantial understanding of otolith microchemistry. Briefly, otoliths consist of approximately $>90 \%$ (typically 90 $96 \%$ ) calcium carbonate by weight, $0.01-10 \%$ (typically $3-4 \%$ ) organic matrix (protein complex) and $\sim 1 \%$ non-organic trace elements (minor and trace elements, including radioisotopes and stable isotopes) (Campana 1999; Chang and Geffen 2013; Payan et al. 1999; Sohn et al. 2005). Otoliths are complex polycrystalline bodies composed of needle-shaped crystals of calcium carbonate, radiating outwards in three dimensions from a centrally located nucleus and passing through a network of fibrous collagen-like protein called otolin (OTO 2007). Otolith calcium carbonate is in the form of twinned aragonite, although abnormal crystalline otoliths are composed of calcite or vaterite (Campana 1999; OTO 2007; Parmentier et al. 2007). Otolin resembles keratin in its amino acid composition and contains water soluble proteins (acidic amino acids) and water insoluble proteins (Campana 1999; OTO 2007).

Otolith element concentration evaluation reveals the interaction between biology and environment in the determination of otolith composition (Chang and Geffen 2013). The elemental composition of otoliths is known to be influenced by physiological processes such as metamorphosis, growth rate, age, food availability, activity levels, diurnal and seasonal cycles, reproductive status and environmental stress (Radtke and Shafer
1992; Tabouret et al. 2011). Species also vary in response to environmental conditions such as temperature and salinity. The chemical composition of the water also may vary in terms of geographic location, depth, salinity and temperature regimes (Chang and Geffen 2013; OTO 2007). Thus the structure and composition of otoliths is influenced by many factors operating at many levels with significant regional variations occurring (Chang and Geffen 2013).

The validity of the calibration models for future predictions depends on how well the calibration set represents the composition of future samples (Liu and Ying 2005). The present study suggests that there is variability in otolith microchemistry between post-wet and post-dry samples. The differences in microchemistry may be attributed to the environmental variations in water composition due to seasonal changes as discussed above (Chang and Geffen 2013; OTO 2007). Model robustness was increased across seasons when greater biological variability was included in the calibration set (combined post-wet and postdry sample sets). As more biological variability is taken into account, the prediction accuracy becomes less sensitive to unknown changes of external factors (Bobelyn et al. 2010). This suggests the development of robust calibration models will require training sets that cover variables such as seasonal otolith growth (post-wet and post-dry), yearly (temporal) differences, fish size, diversified age structure and location variables, and measurement conditions (sample handling and presentation). However, in some cases, the incorporation of more biological variability (at the risk of including atypical data) in the calibration set can significantly reduce the models prediction accuracy (Bobelyn et al. 2010).

The successful development of NIR spectroscopy methods for predicting estimated fish age would provide major benefits over the current ageing determination practices. First, the speed of operation would be greatly increased as whole otolith samples could be assessed without the need for resin mounting and section preparation. This could allow many thousands of assessments to be completed in a week on whole otoliths. This new method also has the potential to minimise greatly the reading error associated with subjective visual interpretation of period growth increments on the otoliths.

Future work will require a broad assessment of this method across a wide range of species from different environments and climates. Should this method prove to be applicable across a broad range of fish species, both of commercial and recreational significance, the reduction in costs and time required to age fish will be a substantial benefit to fishery managers.

\section{Acknowledgements}

The authors would sincerely like to thank staff of the Fisheries Long-term Monitoring Program (Fisheries Queensland) who happily allowed our team access to their specialist equipment, including training and overseeing our results. We would especially like to thank I. Brown, M. McLennan, D. Smallwood, M. Sellin, and S. Wesche for their generous input throughout this investigation. We would also like to thank K. Sarneckis, CEO of the Northern Territory Seafood Council for supporting this work and B. Passey of Australia Bay Seafoods for supplying the fish. The authors would also like to thank the reviewers for generously donating their time and energy to reviewing this work and improving the overall readability of this manuscript. 


\section{References}

Bailleres, H., Davrieux, F., and Ham-Pichavant, F. (2002). Near infrared analysis as a tool for rapid screening of some major wood characteristics in a eucalyptus breeding program. Annals of Forest Science $\mathbf{5 9}$ 479-490. doi:10.1051/FOREST:2002032

Beamish, R. J. (1979). New Information on the Longevity of Pacific Ocean Perch (Sebastes alutus). Journal of the Fisheries Research Board of Canada 36, 1395-1400. doi:10.1139/F79-199

Bobelyn, E., Serban, A.-S., Nicu, M., Lammertyn, J., Nicolai, B. M., and Saeys, W. (2010). Postharvest quality of apple predicted by NIRspectroscopy: Study of the effect of biological variability on spectra and model performance. Postharvest Biology and Technology 55, 133-143. doi:10.1016/J.POSTHARVBIO.2009.09.006

Boehlert, G. W., and Yokavich, M. M. (1984). Variability in age estimates in Sebastes as a function of methodology, different readers, and different laboratories. California Fish and Game 70, 210-224. http://swfsc.noaa. gov/publications/CR/1984/8413.PDF.

Campana, S. E. (1999). Chemistry and composition of fish otoliths: pathways, mechanisms and applications. Marine Ecology Progress Series 188, 263-297. doi:10.3354/MEPS188263

Campana, S. E. (2001). Accuracy, precision and quality control in age determination, including a review of the use and abuse of age validation methods. Journal of Fish Biology 59, 197-242. doi:10.1111/J.10958649.2001.TB00127.X

Campana, S. E., and Thorrold, S. R. (2001). Otoliths, increments, and elements: keys to a comprehensive understanding of fish populations. Canadian Journal of Fisheries and Aquatic Sciences 58, 30-38. doi:10.1139/F00-177

Cardinale, M., Arrhenius, F., and Johnsson, B. (2000). Potential use of otolith weight for the determination of age-structure of Baltic cod (Gadus morhua) and plaice (Pleuronectes platessa). Fisheries Research 45, 239-252. doi:10.1016/S0165-7836(99)00122-8

Chang, M.-Y., and Geffen, A. J. (2013). Taxonomic and geographic influences on fish otolith microchemistry. Fish and Fisheries 14, 458-492. doi:10.1111/J.1467-2979.2012.00482.X

Fisheries-Queensland (2009). Fisheries Long Term Monitoring Program Sampling Protocol - Fish Ageing: Section 2: Snapper. Department of Employment, Economic Development and Innovation, Queensland Government, Brisbane. Available from: http://www.daff.qld.gov.au/ fisheries/monitoring-our-fisheries/commercial-fisheries/species-specificprograms/sampling-protocols/fish-ageing

Folkestad, A., Wold, J. P., Rørvik, K.-A., Tschudi, J., Haugholt, K. H., Kolstad, K., and Mørkøre, T. (2008). Rapid and non-invasive measurements of fat and pigment concentrations in live and slaughtered Atlantic salmon (Salmo salar L.). Aquaculture 280, 129-135. doi:10.1016/ J.AQUACULTURE.2008.04.037

Forrest, A., Poole, S., Exley, P., Mayze, J., and Paulo, C. (2010). Improving profitability to Industry through the identification and management of 'tough' fish syndrome in tropical Saddletail snapper (Lutjanus malabaricus). Innovative Food Technologies, Department of Employment, Economic Development and Innovation, Queensland, Brisbane.

FRDC (2013). Revolutionising fish ageing - milestone report 4. In 'FRDC Project 2012/011'. (Ed. J Robbins). (Commomwealth Fisheries Research and Development Corporation: Canberra).

Gaffey, S. (1986). Spectral reflectance of carbonate minerals in the visible and near infrared (0.35-2.55 microns: calcite, aragonite, and dolomite. The American Mineralogist 71, 151-162.

Golic, M., and Walsh, K. B. (2006). Robustness of calibration models based on near infrared spectroscopy for the in-line grading of stonefruit for total soluble solids content. Analytica Chimica Acta 555, 286-291. doi:10.1016/J.ACA.2005.09.014

Hunt, R. (1977). Spectral signatures of particulate minerals in the visible and near infrared. Geophysics 42, 501-513. doi:10.1190/1.1440721
Liu, Y., and Ying, Y. (2005). Use of FT-NIR spectrometry in non-invasive measurements of internal quality of 'Fuji' apples. Postharvest Biology and Technology 37, 65-71. doi:10.1016/J.POSTHARVBIO. 2005.02.013

McClure, W. F., Crowell, B., Stanfield, D. L., Mohapatra, S., Morimoto, S., and Batten, G. (2002). Near infrared technology for precision environmental measurements: part 1. Determination of nitrogen in green- and dry-grass tissue. Journal of Near Infrared Spectroscopy 10, 177-185. doi:10.1255/JNIRS.333

McGlone, V. A., and Kawano, S. (1998). Firmness, dry-matter and solublesolids assessment of postharvest kiwifruit by NIR spectroscopy. Postharvest Biology and Technology 13, 131-141. doi:10.1016/S0925-5214 (98)00007-6

Moron, A., and Cozzolino, D. (2003). Exploring the use of near infrared reflectance spectroscopy to study physical properties and microelements in soils. Journal of Near Infrared Spectroscopy 11, 145-154 doi:10.1255/JNIRS.362

Murray, I., and Williams, P. (1987). Chemical principles of near-infrared technology. In 'Near infrared technology in the agricultural and food industries'. (Eds P. Williams and K. H. Norris.) pp. 330. (American Association of Cereal Chemists and The University of Wisconsin, Madison, WI.)

Newman, S. J. (2002). Growth rate, age determination, natural mortality and production potential of the scarlet seaperch, Lutjanus malabaricus Schneider 1801, off the Pilbara coast of north-western Australia Fisheries Research 58, 215-225. doi:10.1016/S0165-7836(01)00367-8

Nilsen, H., Esaiassen, M., Heia, K., and Sigernes, F. (2002). Visible/NearInfrared Spectroscopy: A New Tool for the Evaluation of Fish Freshness Journal of Food Science 67, 1821-1826. doi:10.1111/J.1365-2621. 2002.TB08729.X

OTO. (2007). Otolith Training Online. Marine Institute Fisheries Science Services. Available from: http://www.marine.ie/oto/overview/index. htm

Parmentier, E., Cloots, R., Warin, R., and Henrist, C. (2007). Otolith crystals (in Carapidae): Growth and habit. Journal of Structural Biology 159, 462-473. doi:10.1016/J.JSB.2007.05.006

Payan, P., Edeyer, A., De Pontual, H., Borelli, G., Boeuf, G., and MayerGostan, N. (1999). Chemical composition of saccular endolymph and otolith in fish inner ear: lack of spatial uniformity. American Journal of Physiology. Regulatory, Integrative and Comparative Physiology $\mathbf{2 7 7}$, R123-R131. http://ajpregu.physiology.org/content/277/1/R123.full.

Radtke, R. L., and Shafer, D. J. (1992). Environmental sensitivity of fish otolith microchemistry. Australian Journal of Marine and Freshwater Research 43, 935-951. doi:10.1071/MF9920935

Secor, D. H., Dean, J. M., and Campana, S. E. (1995). Recent developments in otolith research. In 'The Belle W. Baruch Library in Marine Science'. (Ed. S. E. Campana.). (University of South Carolina Press: Columbia, SC.)

Sohn, D., Kang, S., and Kim, S. (2005). Stock identification of chum salmon (Oncorhynchus keta) using trace elements in otoliths. Journal of Oceanography 61, 305-312. doi:10.1007/S10872-005-0041-3

Solberg, C., Saugen, E., Swenson, L.-P., Bruun, L., and Isaksson, T. (2003). Determination of fat in live farmed Atlantic salmon using non-invasive NIR techniques. Journal of the Science of Food and Agriculture 83, 692-696. doi:10.1002/JSFA.1363

Tabouret, H., Lord, C., Bareille, G., Pecheyran, C., Monti, D., and Keith, P. (2011). Otolith microchemistry in Sicydium punctatum: indices of environmental condition changes after recruitment. Aquatic Living Resources 24, 369-378. doi:10.1051/ALR/2011137

Thomas, D., McGoverin, C., Chinsamy, A., and Manley, M. (2011). Near infrared analysis of fossil bone from the Western Cape of South Africa Journal of Near Infrared Spectroscopy 19, 151-159. doi:10.1255/ JNIRS.926 
Wedding, B. B., White, R. D., Grauf, S., Tilse, B., and Gadek, P. A. (2009). Near infrared spectroscopy as a rapid, non-invasive method for sandalwood oil determination. SABRAO Journal of Breeding and Genetics 41. http://eprints.jcu.edu.au/5545/

Wedding, B. B., White, R. D., Grauf, S., Wright, C., Tilse, B., Hofman, P., and Gadek, P. A. (2011). Non-destructive prediction of 'Hass' avocado dry matter via FT-NIR spectroscopy. Journal of the Science of Food and Agriculture 91, 233-238. doi:10.1002/JSFA.4175

Williams, P. (2004). 'Near-Infrared Technology: Getting the Best Out of Light.' (Value Added Wheat CRC, Limited: Nanaimo, Canada)
Wold, J. P., and Isaksson, T. (1997). Non-destructive determination of fat and moisture in whole Atlantic salmon by near-infrared diffuse spectroscopy. Journal of Food Science 62, 734-736. doi:10.1111/J.13652621.1997.TB15446.X

Wold, J. P., Jakobsen, T., and Krane, L. (1996). Atlantic salmon average fat content estimated by near-infrared transmittance spectroscopy. Journal of Food Science 61, 74-77. doi:10.1111/J.1365-2621.1996. TB14728.X 